Composites Part A: Applied Science and Manufacturing February 2006; 37(2) : 337-343

http://dx.doi.org/10.1016/i.compositesa.2005.03.026

(c) 2005 Elsevier Ltd All rights reserved
Archimer, archive institutionnelle de l'Ifremer http://www.ifremer.fr/docelec/

\title{
Characterization of residual stresses in wound composite tubes
}

\author{
P. Casari ${ }^{\mathrm{a}}$, F. Jacquemin ${ }^{\mathrm{a}}$ and P. Davies ${ }^{\mathrm{b}}$
}

\author{
${ }^{\mathrm{a}} \mathrm{GeM}$, Institut de Recherche en Génie Civil et Mécanique - UMR CNRS 6183, 2, rue de la Houssinière, BP \\ 92208, 44322 Nantes Cedex 03, France \\ ${ }^{\mathrm{b}}$ IFREMER Centre de Brest, BP 70, 29280 Plouzané, France \\ *: Corresponding author : Fax: +33 02511255 57. pascal.casari@physique.univ-nantes.fr
}

\begin{abstract}
This paper presents a method for the characterization of residual stresses in thick filament wound tubes. The three materials considered in the study are wet wound epoxy composite tubes based on E glass, R glass and T700 carbon fibres with three winding angles, $[ \pm 35],[ \pm 55]$ and $[ \pm 85]$ with respect to the longitudinal axis. The aim of the present work is to measure internal stresses, based on strains liberated by cutting composite tubes, and to compare results with predictions from a residual stress model based on the classical equations of solid mechanics. This leads to a simple technique which allows the quick identification of the effects of manufacturing and moisture on the internal multi-axial stress level.
\end{abstract}

Keywords: Residual stress; Composite; Tube; Moisture 


\section{Introduction}

The increasing use of composite laminates in engineering applications, due to their high strength-to-weight ratio as well as excellent corrosion and fatigue resistance, has resulted in greater interest in their long term behaviour. Composites tubes are widely used for a range of industrial applications and have been the subject of many previous studies. The manufacture of composite tubes by filament winding generates process-induced stresses. When curing is completed, the tubes are then subjected to ambient conditions which may generate hygrothermal internal stresses which add to the residual manufacturing stresses. When polymer matrix composites are exposed to elevated temperatures and wet environments they undergo dimensional and stress state changes due to moisture induced swelling and thermal expansion. Such stresses can have a significant effect on the mechanical performance of composite structures by inducing warpage and initiating matrix cracks and delaminations. However it is not a trivial task to measure internal stresses accurately during the service life of composite structures. The aim of the present study is to measure internal stresses and to compare them to numerical predictions. An experimental investigation into internal stress measurement is described here, based on measuring the strains revealed by cutting composite tubes. Axial and transverse cuts release the strains caused by internal stresses. The corresponding residual stress model, based on continuum mechanics within the framework of hygrothermoelasticity, is presented. Then the comparison is given through the calculation of axial and circumferential bending moments.

\section{Experimental study}

\subsection{Principle of residual stresses characterisation}

Many techniques have been developed to measure internal stresses. Embedded sensors such as optical fibres [1] and strain gages have been used to measure the local internal stress state. 
At a ply or macroscopic scale the hole drilling method [2], the layer removal method [3] and the compliance method [4] have been used in the past. The experimental technique used in the current work is similar to the compliance method and consists of sectioning the tubes (Figure 1) and measuring the change in strains on the external and internal surfaces with two biaxial strain gages, one bonded to each side of the tube wall (Figure 2). This leads to the estimation of axial and circumferential internal bending moments in order to give an order of magnitude of quantities commonly used in industrial design for the calculation of the properties of filament wound tubes.

\subsection{Testing operation}

The test chosen to reveal residual stresses is a destructive one. It involves removing all the tube surrounding the area on which strain gages are bonded. A series of cuts is performed, and strains follow a non-monotonic evolution which depends on the order of cutting operations. The testing procedure is detailed below in order to analyse accurately the effect of each step by taking the typical response of a $\mathrm{R}$ glass tube, with a stacking sequence of $[ \pm 85]$, equipped with strain gages during cutting:

- $1^{\text {st }}$ step: Samples. The length of the tube is chosen to ensure that the cut of a first ring at the edge has no effect on the internal strains measured in the middle by strain gages. The tubes are $55 \mathrm{~mm}$ diameter and $6.5 \mathrm{~mm}$ thickness, The minimum length of the tubes was $76 \mathrm{~mm}$.

- $2^{\text {nd }}$ step: Instrumentation. Biaxial strain gages are bonded and sealed in the middle of the piece of tube on the inside and outside surfaces. Strain gages have a grid length of $5 \mathrm{~mm}$ and a supporting area of $10 \mathrm{~mm}$ diameter. An HBM Spider8 ${ }^{\mathrm{TM}}$ data acquisition system is used for strain gage quarter bridge conditioning. The electric supply is based upon a carrier frequency principle which ensures that even on glass-epoxy material, 
which has a lower thermal conductivity than carbon-epoxy, there is no drift of the signal due to strain gage heating. Before handling and clamping the tube, the gage readings are set at zero.

- $3^{\text {rd }}$ step: Machining. A series of cuts are made in a convenient order for machining (Figure 3). A lubricated diamond saw is mounted on the machine instead of the regular tool (Figure 4). The cut is obtained by the rotation of the saw and only one turn of the chuck, so that the wires of the strain gages remain long enough to follow the motion of the tube. The following numbers refer to Figure 3 and Figure 5.

(0) - The tube is clamped in the chuck of the lathe.

(1-4) - Four rings are cut from the end of the tube. The rings are $6 \mathrm{~mm}$ wide and the saw is $2.5 \mathrm{~mm}$ thick, so the total thickness of the removed material is $8.5 \mathrm{~mm}$. The last ring cut is stopped as close as possible to the support of the strain gage. Several rings were cut in order to ensure that the tube was sufficiently long to avoid end effects.

(5) - A fifth cut is done as close as posible to the strain gages.

(6) - The remaining part of the tube is unclamped from the lathe.

(7) - A cut is made parallel to the $\mathrm{x}$ axis in order to open the tube.

(8-9) - The last two cuts are made around the strain gages, and there remains only a square piece of material on which a zero stress state is assumed.

The strains reported in Table 1 correspond to those measured after the end of all cutting operations.

The first observations are:

- A significant strain level with hundreds of microstrains is measured.

- Tubes tend to close after axial cuts.

- The transverse cuts generate mostly a relaxation of the longitudinal strains and the longitudinal cuts generate a relaxation of the transverse strains. 
- Strains from inner and outer surfaces are roughly opposite to each other, except for the carbon tubes, for which a thermal drift seems to exist. Different heat transfer conditions may explain the difference compared with glass tubes.

\subsection{Results from experiments}

Table 1 shows the inner and outer circumferential and axial final strains for nine epoxy composite tubes, reinforced with E glass, R glass and T700 carbon fibres. Three winding angles are considered, $\left[ \pm 55^{\circ}\right],\left[ \pm 35^{\circ}\right]$ and $\left[ \pm 85^{\circ}\right]$ with respect to the tube axis. The tubes were manufactured in 1998 applying a cure temperature of $125^{\circ} \mathrm{C}$ for 7 hours, then stored at ambient temperature for five years.

The strains are generally negative on the inner surfaces of the tubes while the strains on the outer surfaces of the tubes are generally positive. Global equilibrium considerations ensure that only bending internal loads are released from cut-outs. Indeed axial and circumferential loads are released because of free boundary conditions. However, strains measured inside and outside which should be opposite to each other don't respect this. Table 1 gives also the calculation results of membrane and bending strains (defined on Figure 2). This may be due to a thermal drift of the strain gages due to the machining warm up, even if lubricant is removing heat from the tube. Then, only the bending part of strains is considered for the comparison with simulations in the next sections. Moreover, only one test could be performed on each type of tube, which may lead to some potential errors in strain results.

\section{Numerical study}

\subsection{Process-induced stresses}

A model has been developed in parallel with the experimental study, which predicts the stress level in the constitutive plies of the tube. The residual stresses, induced by the temperature 
differential (between cure and room temperatures), for each ply at any time, are calculated by using the classical equations of solid mechanics (see reference [5] for details): constitutive laws of thermoelastic orthotropic materials (1), strain-displacement relationship, compatibility and equilibrium equations and boundary conditions.

The constitutive laws of a thermoelastic orthotropic material are given as follows:

$$
\sigma=\mathbf{L}:\left(\varepsilon-\alpha\left(\mathrm{T}-\mathrm{T}_{0}\right)\right)
$$

where $\alpha$ and $\mathbf{L}$ are respectively the tensors of thermal expansion coefficients and stiffness. $\alpha$ and $\mathbf{L}$ are assumed to be constants.

At the beginning of the cool-down, a stress-free state is assumed. Previous studies have considered the material behavior of a thermosetting resin during cure to be highly viscoelastic, the residual stresses to be immediately relaxed and stress-free conditions to exist at the cure temperature so that an elastic model may be sufficient to predict residual stresses during cool-down [6]. This is a strong assumption but little experimental data is available to allow alternative initial conditions to be defined, though results from a recent study suggest that it may be possible to design experiments to verify this [7].

The axial and circumferential components of the displacement field of the $i^{\text {th }}$ ply, respectively $u$ and $v$, are then expressed:

$$
\left\{\begin{array}{l}
\mathrm{u}=\mathrm{R}_{1} \mathrm{x} \\
\mathrm{v}=\mathrm{R}_{2} \mathrm{xr} \\
\mathrm{R}_{1}, \mathrm{R}_{2} \text { are constants. }
\end{array}\right.
$$

The radial component of the displacement field $w$ satisfies the following equation:

$$
\mathrm{r}^{2} \frac{\partial^{2} \mathrm{w}}{\partial \mathrm{r}^{2}}+\mathrm{r} \frac{\partial \mathrm{w}}{\partial \mathrm{r}}-\frac{\mathrm{L}_{\theta \theta}}{\mathrm{L}_{\mathrm{rr}}} \mathrm{w}=\frac{\left(\mathrm{L}_{\mathrm{x} \theta}-\mathrm{L}_{\mathrm{xr}}\right) \mathrm{R}_{1} \mathrm{r}+\left(\mathrm{L}_{\mathrm{s} \theta}-2 \mathrm{~L}_{\mathrm{rs}}\right) \mathrm{R}_{2} \mathrm{r}^{2}}{\mathrm{~L}_{\mathrm{rr}}}+\frac{\operatorname{Kr}\left(\mathrm{T}-\mathrm{T}_{0}\right)}{\mathrm{L}_{\mathrm{rr}}}
$$

with, $\mathrm{K}=\left(\mathrm{L}_{\mathrm{xr}}-\mathrm{L}_{\mathrm{x} \theta}\right) \alpha_{\mathrm{xx}}+\left(\mathrm{L}_{\mathrm{r} \theta}-\mathrm{L}_{\theta \theta}\right) \alpha_{\theta \theta}+\left(\mathrm{L}_{\mathrm{rr}}-\mathrm{L}_{\mathrm{r} \theta}\right) \alpha_{\mathrm{rr}}+\left(\mathrm{L}_{\mathrm{rs}}-\mathrm{L}_{\mathrm{s} \theta}\right) \alpha_{\mathrm{x} \theta}$. 
It is shown that the general solution of equation (3) can be written as the sum of a solution of the homogeneous equation and of a particular solution.

$$
\begin{aligned}
\mathrm{w}(\mathrm{r}) & =\mathrm{R}_{3} \mathrm{r} \sqrt{\frac{\mathrm{L}_{\theta \theta}}{\mathrm{L}_{\mathrm{rr}}}}+\mathrm{R}_{4} \mathrm{r} \\
& +\frac{\left(\mathrm{L}_{\mathrm{x} \theta}-\mathrm{L}_{\mathrm{xr}}\right) \mathrm{R}_{1} \mathrm{r}}{\left(\mathrm{L}_{\mathrm{rr}}-\mathrm{L}_{\theta \theta}\right)}+\frac{\left(\mathrm{L}_{\mathrm{s} \theta}-2 \mathrm{~L}_{\mathrm{rs}}\right) \mathrm{R}_{2} \mathrm{r}^{2}}{\left(4 \mathrm{~L}_{\mathrm{rr}}-\mathrm{L}_{\theta \theta}\right)}+\frac{\mathrm{Kr}}{\left(\mathrm{L}_{\mathrm{rr}}-\mathrm{L}_{\theta \theta}\right)}\left(\mathrm{T}-\mathrm{T}_{0}\right)
\end{aligned}
$$

Finally for an n-layer tube the displacement field depends on $4 n$ constants $\left(\mathrm{R}_{1}, \mathrm{R}_{2}, \mathrm{R}_{3}\right.$ and $\left.\mathrm{R}_{4}\right)$ to be determined. The constants are calculated from the following conditions [5]:

- traction-free conditions at the inner and outer radii and continuity of the radial stress at each interply ;

- continuity of the displacement components at each interface between adjacent plies ;

- global force balance of the cylinder.

\subsection{Internal stresses generated by the ambient conditions}

When curing is completed, the tube is exposed to the environmental conditions. Ambient conditions generate internal stresses which add to the residual manufacturing stresses. The internal stresses in the tube wall are computed within the framework of hygroelasticity. We consider an orthotropic hygroelastic constitutive law (5), strain-displacement relationship and compatibility and equilibrium equations [8].

The constitutive laws of a hygroelastic orthotropic material are given as follows:

$$
\sigma=\mathbf{L}:\left(\varepsilon-\beta\left(\mathrm{m}-\mathrm{m}_{0}\right)\right)
$$

where $\beta$ and $\mathbf{L}$ are respectively the tensors of hygroscopic expansion coefficients and stiffness and $\mathrm{m}$ the moisture content. $\beta$ and $\mathbf{L}$ are assumed to be constants. 


\subsection{Example}

The properties of the three materials used for the simulations are presented in Table 2. An example of a predicted stress distribution in a $[ \pm 55]$ E glass/epoxy tube due to cooling from $125^{\circ} \mathrm{C}$ to $20^{\circ} \mathrm{C}$ is shown in Figure 6 . This shows that shear stresses are not negligible and must be considered at the design stage.

The traction-free conditions imply that the radial stress and the shear stresses in the planes $(\mathrm{r}, \theta)$ and $(\mathrm{x}, \mathrm{r})$ are null at the inner and outer radii. Moreover, these shear stresses are null through the thickness of the pipe. The inplane shear stress $(\mathrm{x}, \theta)$, corresponding to the Figures 6 and 7 , is not affected by these traction-free conditions.

Modelling the change of the moisture concentration from the dry conditions to saturation at an ambient humidity of $50 \%$ [9] indicates compressive stresses which counteract the residual manufacturing stresses (Figure 7). This shows that the residual stress state can vary significantly during the service life of tubes such as these.

\section{Comparison between experimental and numerical approaches}

To make a comparison between experimental and predicted behaviour, the corresponding bending moments are calculated by the following relations (thin tubes are considered) [10] :

$$
\left\{M_{x}=\int_{\frac{-H}{2}}^{\frac{H}{2}} \sigma_{x x} z d z \text { and } M_{\theta}=\int_{\frac{-H}{2}}^{\frac{H}{2}} \sigma_{\theta \theta} z d z\right.
$$

where $\mathrm{H}$ is the thickness of the tube. 
Figure 8 shows a comparison for the bending moments between the experimental and numerical results. The experimental bending moments are deduced from the measured strains and the corresponding stresses are calculated by using the classical laminate theory. The order of magnitude of these moments is significant and needs to be taken into account in design. The results show reasonable agreement for all cases. Experimental errors due to the high sensitivity of strain gages to temperature transitions may affect some of the reported data (Table 1), especially the so-called "membrane strains" which may be produced by local temperature changes during cutting. The remaining mismatch may be reduced by improved characterisation of the hygrothermal properties of the composite tubes. For example, for the simulations, a transverse coefficient of moisture expansion $(\beta)$ of 0.4 is used. The influence of this coefficient on the calculated internal stresses and thus on the corresponding bending moments is illustrated in Figure 9.

All the properties presented in Table 2 are retained except the transverse coefficient of moisture expansion which is allowed to take values of $0.2,0.4$ or 0.6 . The stacking sequence considered is $[ \pm 55]_{9}$ with respect to the longitudinal axis. A coefficient of moisture expansion of 0.6 can induce a change of the stress sign (Figure $9 \mathrm{~d}$ ). Since the internal stress depends so strongly on this coefficient, it must be accurately known in order to achieve good agreement with experimental results. The intralaminar shear stress, non- zero on the inner and outer surfaces whatever the transverse coefficient of moisture expansion, is characteristic of the ply anisotropy and stacking sequence [11].

\section{Conclusion}

This paper presents a simple method to measure the internal stress state in composite tubes. The internal stresses due to the manufacturing process and the environmental conditions are revealed by cutting the composite tubes and measuring corresponding strains by means of 
strain gages. They appear to be signficant and should be taken into account in design of structures made of such tubes. A comparison with an hygrothermoelastic stress model shows reasonable agreement for glass reinforced composite tubes, particularly in the hoop direction. Some higher discrepancies are observed for carbon/epoxy tubes but these may be reduced by improved characterization of the hygrothermal properties, in particular the coefficient of moisture expansion, and by improved representation of material behaviour in the numerical model (viscoelasticity, ageing, damage...). Temperature and moisture may affect mechanical behaviour and cause stress relaxation, especially in the long term. Improved identification of the point during the cure cycle at which stresses start to build up would also improve the model. Further studies are examining these parameters, but the proposed approach makes it possible to check the influence of time-variable process temperature and pressure, and hygrothermal in-service conditions on the behaviour of polymer matrix composites.

\section{References}

1. Vacher S, Gagnaire H, Molimard J, Vautrin A. Embedded fibre optic sensors for real time RFI process monitoring. In: Proceedings of Structural Health Monitoring, First European Workshop. Cachan, July, 2002.

2. Sicot O, Cherouat A, Gong XL, Lu J. Determination of residual stresses in composite laminates using the incremental hole-drilling method. Journal of Composite Materials 2003; 27:575-598.

3. Manson J-A, Seferis JC. Process simulated laminate (PSL): a methodology to internal stress characterization in advanced composite materials. Journal of Composite Materials $1992 ; 26: 405-431$. 
4. Ersoy N, Vardar, O. Measurement of residual stresses in layered composites by compliance method. Journal of Composite Materials 2000; 34:575-598.

5. Hyer MW, Rousseau CQ. Thermally induced stresses and deformations in angle-ply composite tubes. Journal of Composite Materials 1987; 21:454-480.

6. White SR, Kim YK. Process-induced residual stress analysis of AS4/3501-6 composite material. Mechanics of Composite Materials and Structures 1998; 5:153-186.

7. Gigliotti M, Wisnom MR, Potter KD, Development of curvature during the cure of AS4/8552 [0/90] unsymmetric composite plates, Comp. Sci \& Tech 63, 2003, pp187-197.

8. Jacquemin F, Vautrin A. A closed-form solution for the internal stresses in thick composite cylinders induced by cyclical environmental conditions. Composite Structures 2002; 58:1-9.

9. Davies P, Baizeau R, Choqueuse D, Salmon F, Nagot F. Aging and long term behaviour of composite tubes. In: Proceedings of DURACOSYS 99. Bruxelles, July, 2000. p.143-151.

10. Hyer MW. Laminated Plate and Shell Theory. In: Chou TW, editor. Comprehensive Composite Materials. Elsevier Science Publishers, 2000, ch.18, vol.1.

11. Jacquemin, F. and Vautrin, A. Analytical calculation of the transient thermoelastic stresses in thick walled composite pipes, Journal of Composite Materials 2004, 38 : 1733-1751. 


\section{Figures}

Figure 1. Release of bending moments due to internal stresses.

Figure 2. Piece of tube and biaxial strain gages bonded on each side of the tube surface.

Figure 3. Cutting operations on the tube

Figure 4. Saw mounted on the lathe

Figure 5. Typical response of a tube equipped with strain gages during cutting.

Figure 6. Stress distribution in a $[ \pm 55]$ E glass/epoxy tube - Cooling from $125^{\circ} \mathrm{C}$ to $20^{\circ} \mathrm{C}$.

Figure 7. Stress distribution in a $[ \pm 55]$ E glass/epoxy tube at saturation.

Figure 8. Comparison between tests and calculations for bending moments.

Figure 9. Influence of the T700/epoxy transverse coefficient of moisture expansion on the calculated internal stresses : (a) residual stresses with no hygroscopic expansion, (b) $\beta_{2}=0.2$, (c) $\beta_{2}=0.4$, (d) $\beta_{2}=0.6$. 


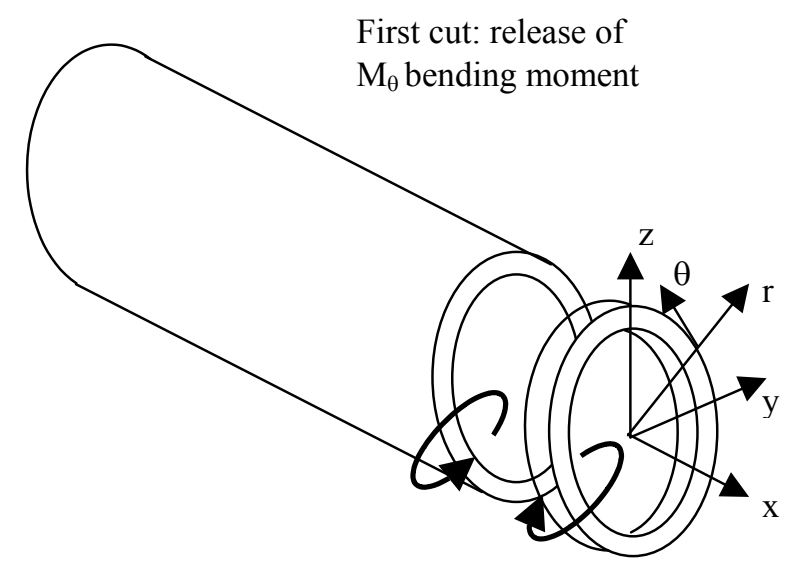

Second cut: release of the remaining part of $\mathrm{M}_{\mathrm{x}}$ bending moment

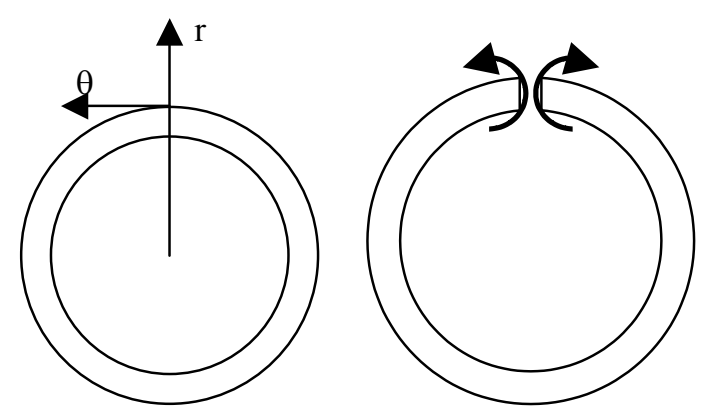

Figure 1. Release of bending moments due to internal stresses.

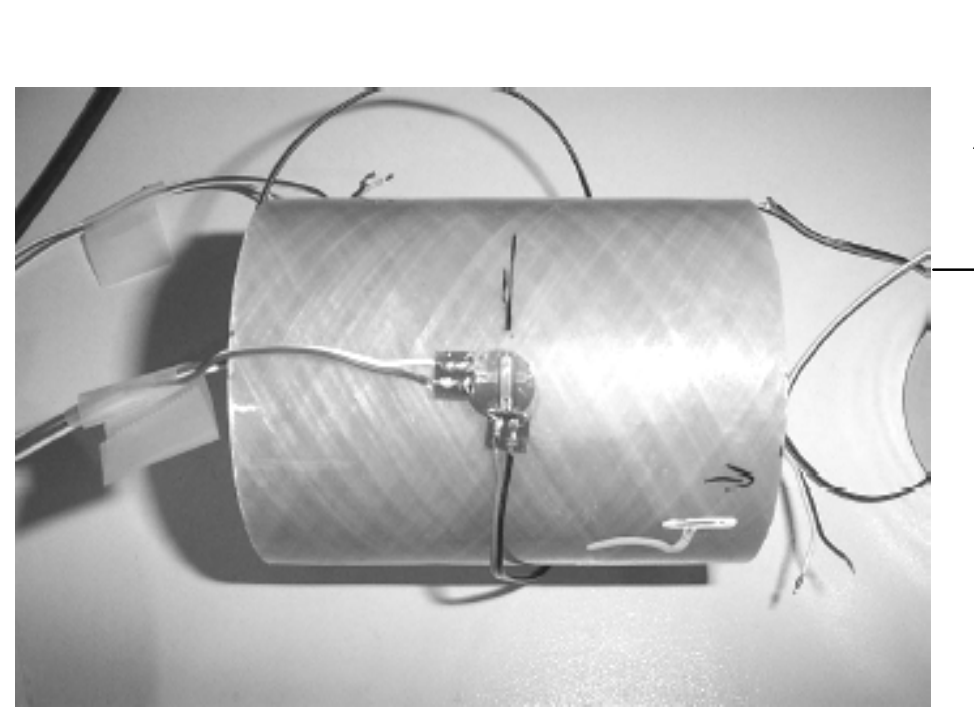

OUTER - INNER

$\varepsilon_{\theta \theta}{ }^{\mathrm{O}}$

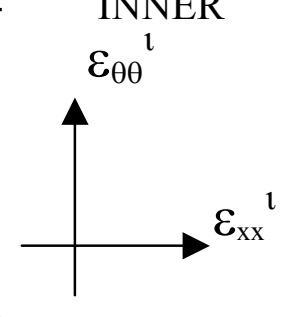

Membrane strains :

$\varepsilon_{x x}^{M}=\frac{\varepsilon_{x x}^{o}+\varepsilon_{x x}^{i}}{2} \quad \varepsilon_{\theta \theta}^{M}=\frac{\mathcal{E}_{\theta \theta}^{o}+\varepsilon_{\theta \theta}^{i}}{2}$

Bending strains :

$\varepsilon_{x x}=\frac{\mathcal{E}_{x x}^{o}-\mathcal{E}_{x x}^{i}}{2} \quad \varepsilon_{\theta \theta}=\frac{\mathcal{E}_{\theta \theta}^{o}-\mathcal{E}_{\theta \theta}^{i}}{2}$

Figure 2. Piece of tube and biaxial strain gages bonded on each side of the tube surface. 


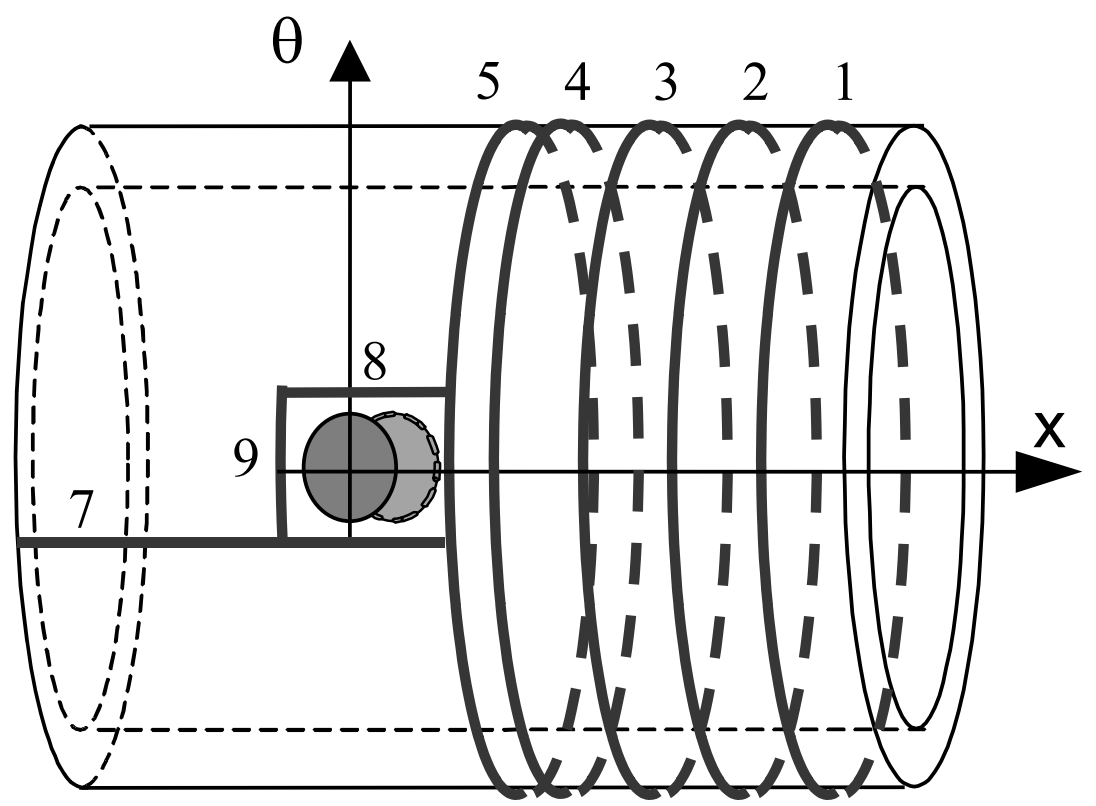

Figure 3. Cutting operations on the tube

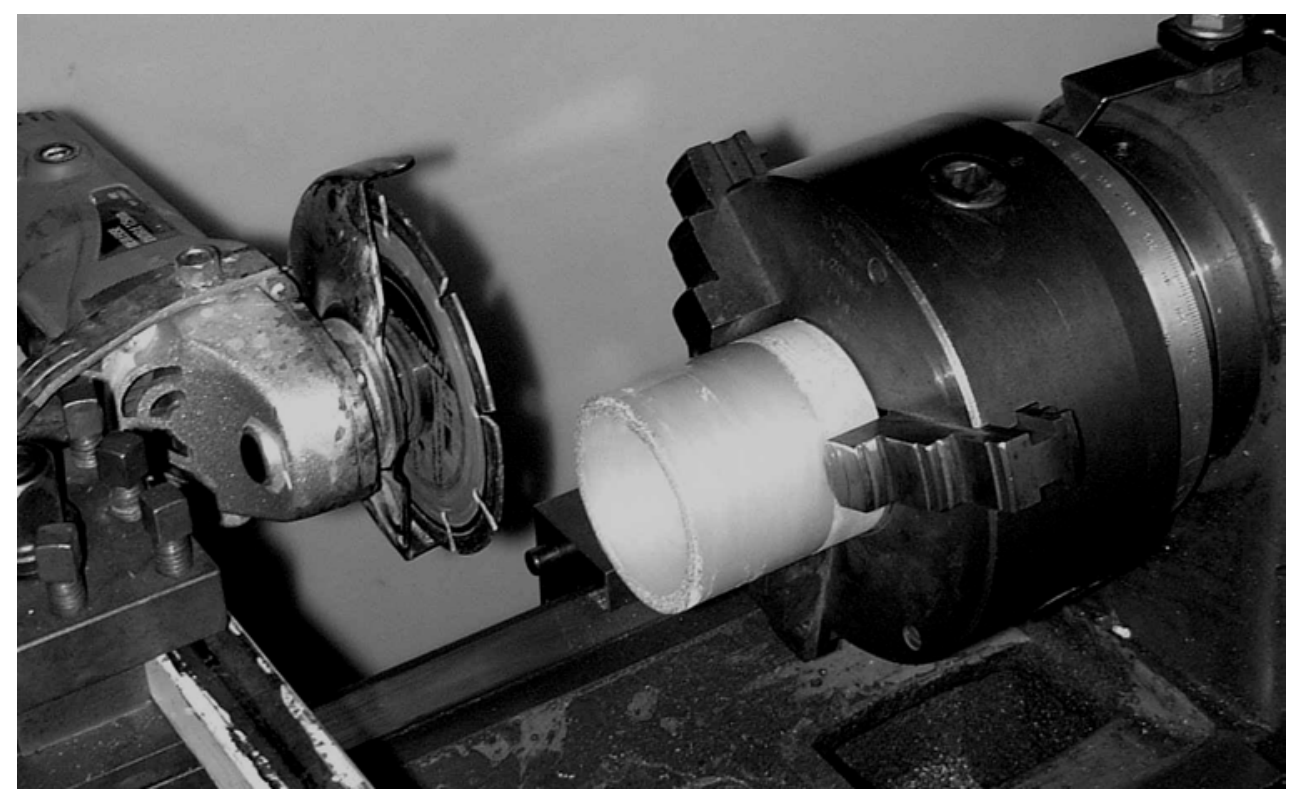

Figure 4. Saw mounted on the lathe 
$\varepsilon$ (Microstrain)

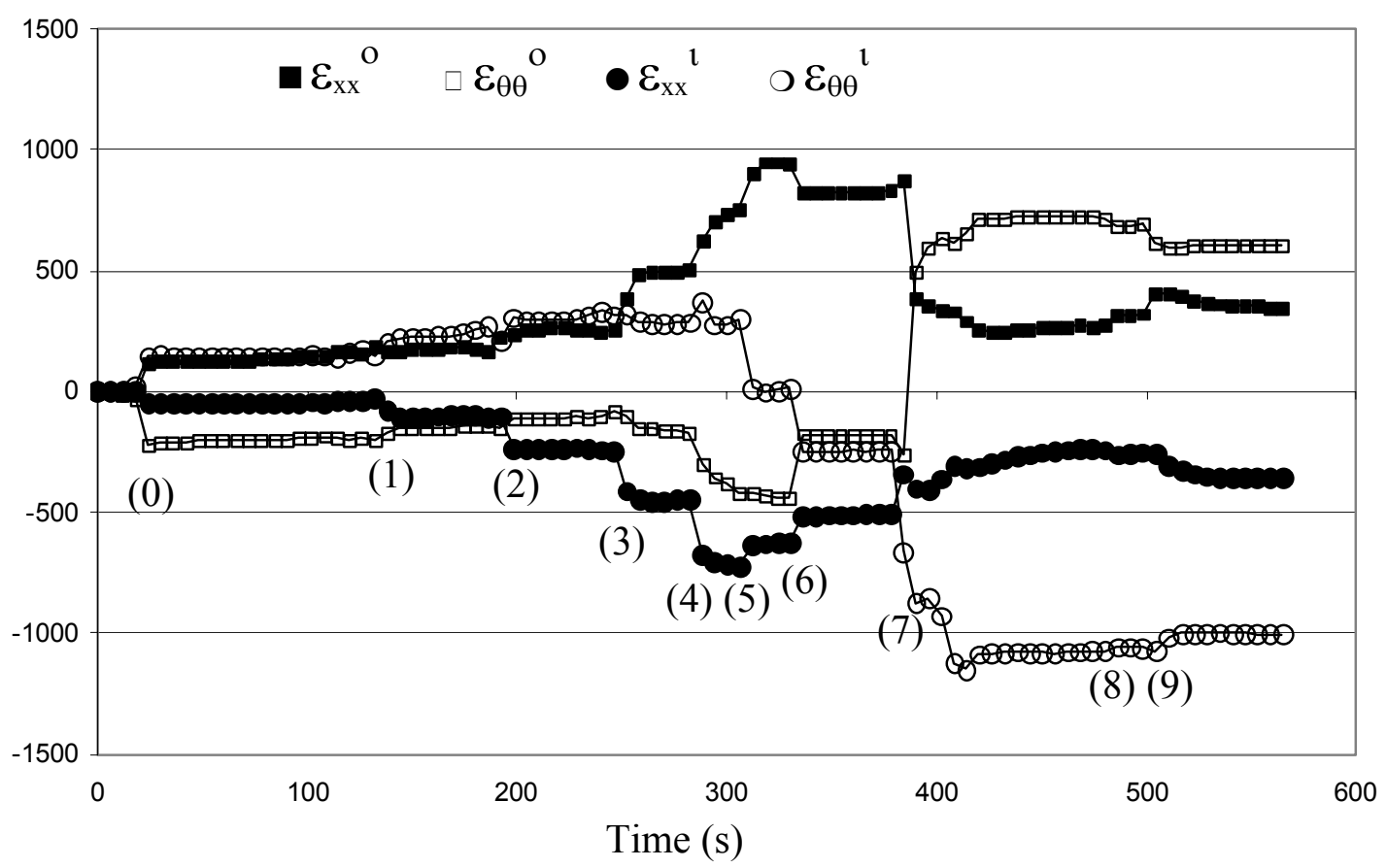

Figure 5. Typical response of a tube equipped with strain gages during cutting. 


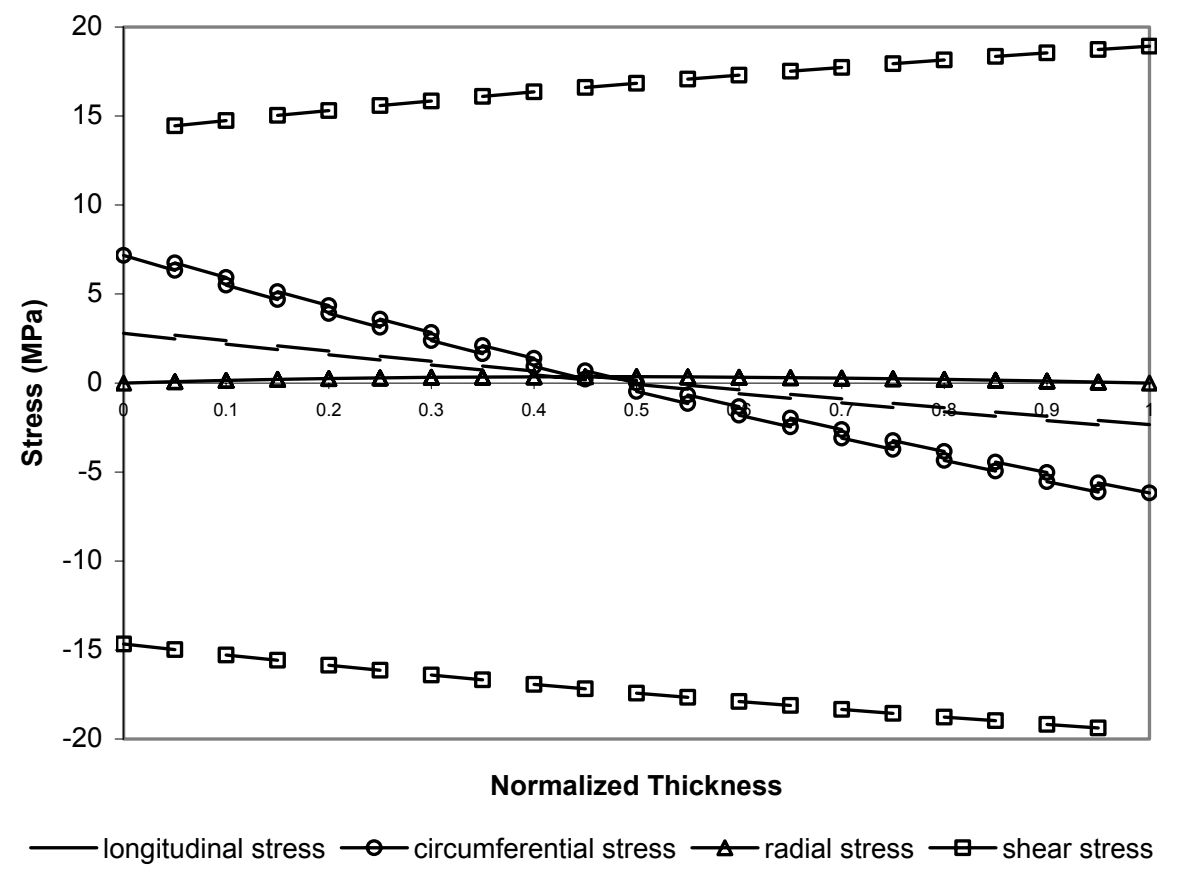

Figure 6. Stress distribution in a $[ \pm 55]$ E glass/epoxy tube - Cooling from $125^{\circ} \mathrm{C}$ to $20^{\circ} \mathrm{C}$.

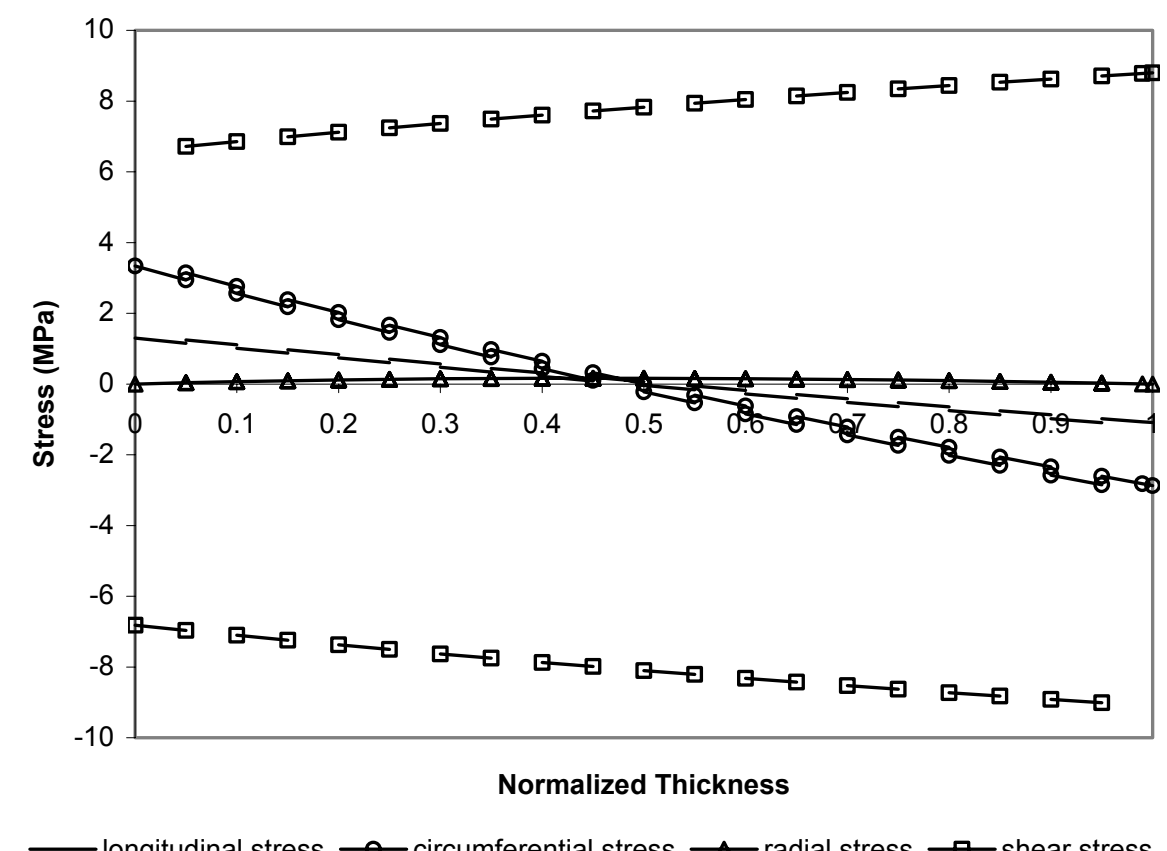

Figure 7. Stress distribution in a $[ \pm 55]$ E glass/epoxy tube at saturation. 


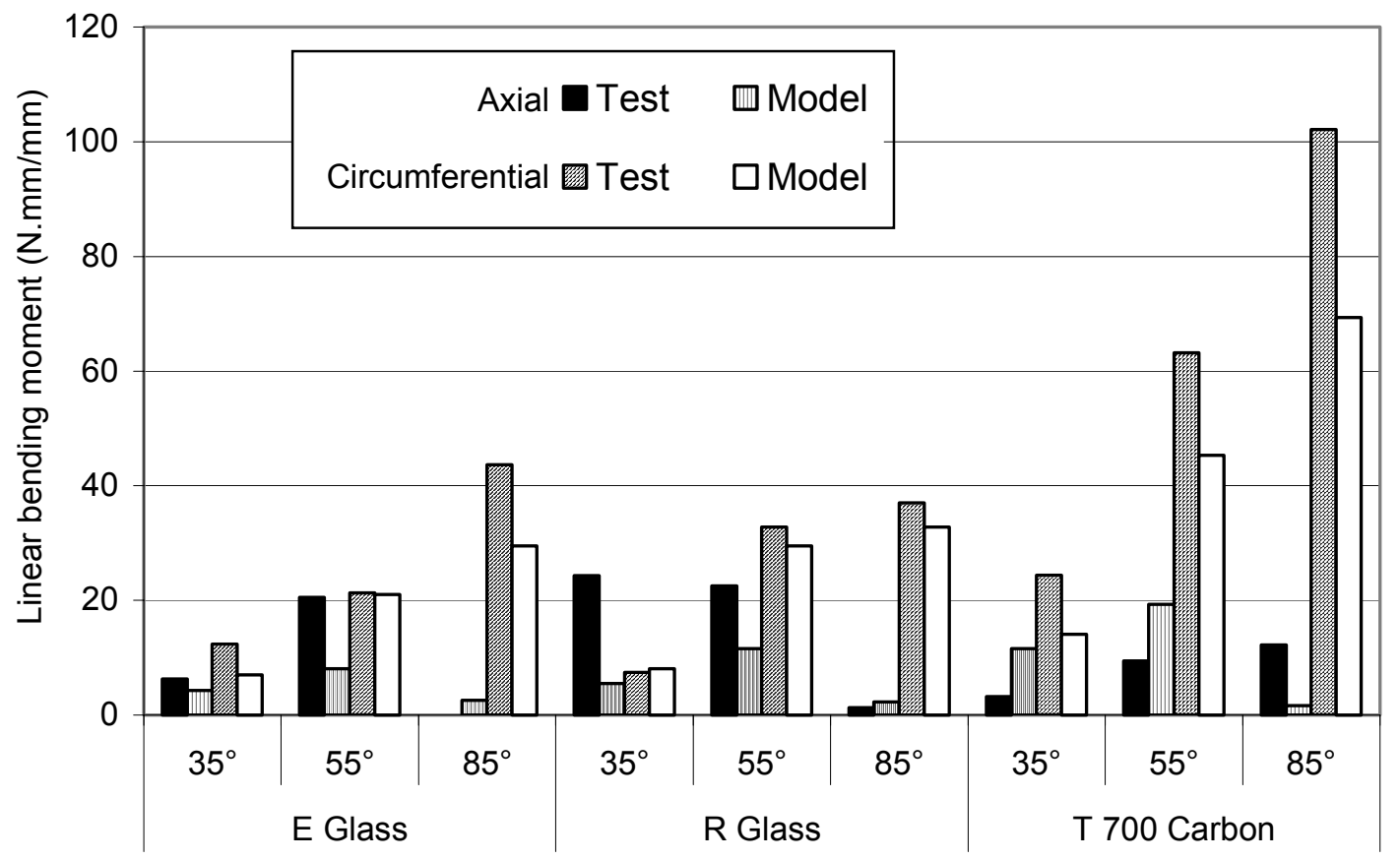

Figure 8. Comparison between tests and calculations for bending moments. 

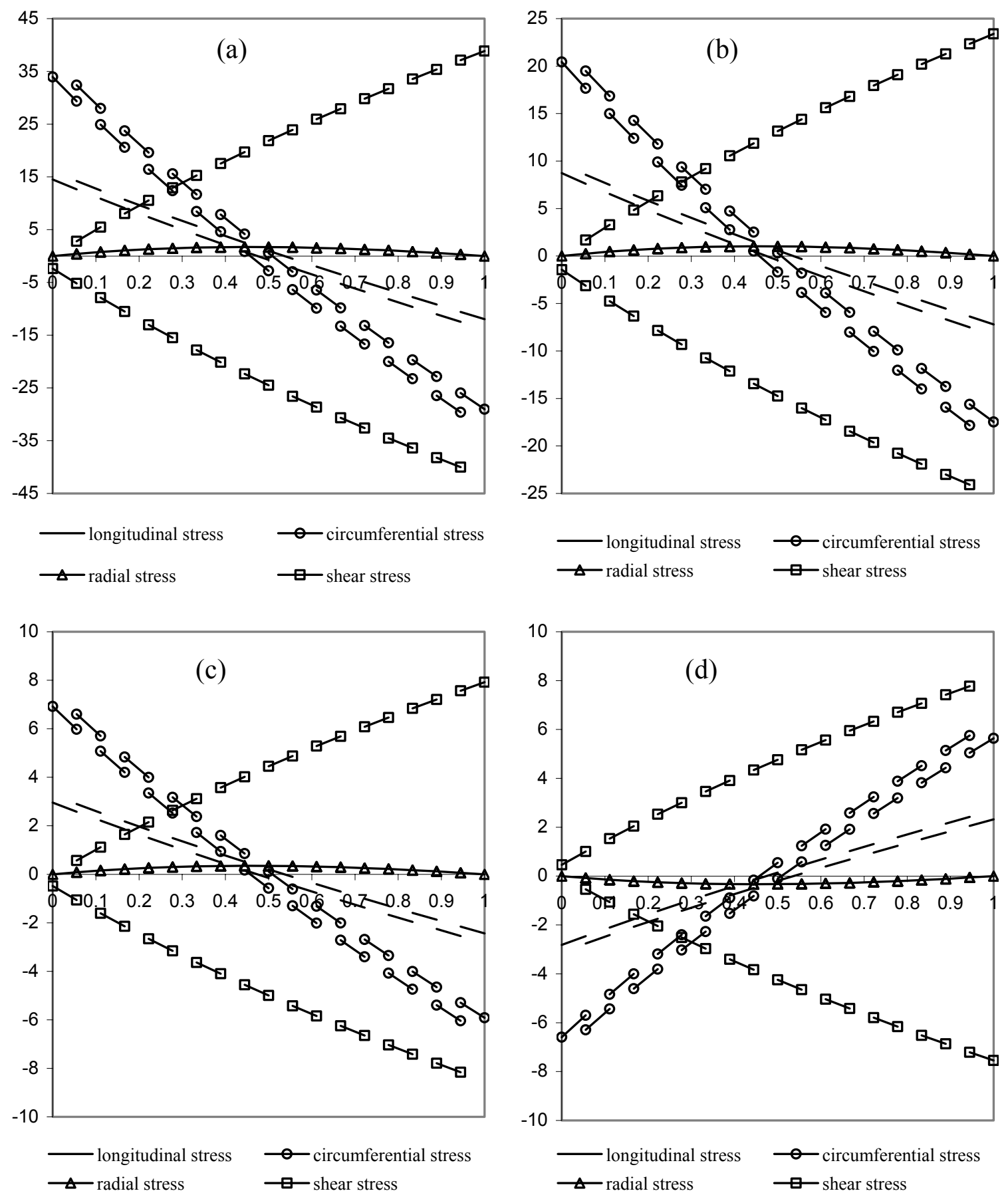

Figure 9. Influence of the T700/epoxy transverse coefficient of moisture expansion on the calculated internal stresses :

(a) residual stresses with no hygroscopic expansion,

(b) $\beta_{2}=0.2$, (c) $\beta_{2}=0.4$, (d) $\beta_{2}=0.6$. 


\section{Tables}

Table 1 Inner and outer strains for three composite materials and three winding angles. Strains measured after all cutting operations.

Table 2 Properties used for the simulations.

\begin{tabular}{|c|c|c|c|c|c|}
\hline Material & Winding angle & $\begin{array}{c}\text { Inner Strains } \\
* 10^{6} \\
\varepsilon_{\mathrm{xx}}{ }^{\mathrm{i}}= \\
\varepsilon_{\theta \theta}{ }^{\mathrm{i}}=\end{array}$ & $\begin{array}{c}\text { Outer Strains } \\
* 10^{6} \\
\varepsilon_{\mathrm{xx}}{ }^{\mathrm{o}}= \\
\varepsilon_{\theta \theta}{ }^{\mathrm{o}}=\end{array}$ & $\begin{array}{c}\text { Membrane } \\
\text { strains } * 10^{6} \\
{ }^{\mathrm{M}}= \\
\varepsilon_{\mathrm{xx}}{ }^{\mathrm{M}}= \\
\varepsilon_{\theta \theta}=\end{array}$ & $\begin{array}{c}\text { Bending } \\
\text { strains } * 10^{6} \\
\varepsilon_{\mathrm{xx}}= \\
\varepsilon_{\theta \theta}=\end{array}$ \\
\hline \multirow{3}{*}{ E glass } & $\pm 35^{\circ}$ & $\begin{array}{c}-62 \\
-296\end{array}$ & $\begin{array}{c}9 \\
270\end{array}$ & $\begin{array}{c}-26.5 \\
-13\end{array}$ & $\begin{array}{l}-35.5 \\
-283\end{array}$ \\
\hline & $\pm 55^{\circ}$ & $\begin{array}{c}-79 \\
-600 \\
\end{array}$ & $\begin{array}{c}60 \\
500 \\
\end{array}$ & $\begin{array}{l}-9.5 \\
-50 \\
\end{array}$ & $\begin{array}{l}-69.5 \\
-550 \\
\end{array}$ \\
\hline & $\pm 85^{\circ}$ & $\begin{array}{c}160 \\
-640\end{array}$ & $\begin{array}{c}18 \\
550\end{array}$ & $\begin{array}{r}89 \\
-45 \\
\end{array}$ & $\begin{array}{c}71 \\
-595 \\
\end{array}$ \\
\hline \multirow{3}{*}{$\mathrm{R}$ glass } & $\pm 35^{\circ}$ & $\begin{array}{c}-72 \\
-560\end{array}$ & $\begin{array}{c}34 \\
550\end{array}$ & $\begin{array}{c}-19 \\
-5\end{array}$ & $\begin{array}{l}-53 \\
-555\end{array}$ \\
\hline & $\pm 55^{\circ}$ & $\begin{array}{l}-300 \\
-390\end{array}$ & $\begin{array}{l}270 \\
470\end{array}$ & $\begin{array}{c}-15 \\
40\end{array}$ & $\begin{array}{l}-285 \\
-430\end{array}$ \\
\hline & $\pm 85^{\circ}$ & $\begin{array}{c}170 \\
-590 \\
\end{array}$ & $\begin{array}{c}6 \\
390 \\
\end{array}$ & $\begin{array}{c}88 \\
-100 \\
\end{array}$ & $\begin{array}{c}82 \\
-490 \\
\end{array}$ \\
\hline \multirow{3}{*}{ Carbon T700 } & $\pm 35^{\circ}$ & $\begin{array}{l}-74 \\
150\end{array}$ & $\begin{array}{c}18 \\
550\end{array}$ & $\begin{array}{l}-28 \\
350\end{array}$ & $\begin{array}{c}-46 \\
-200\end{array}$ \\
\hline & $\pm 55^{\circ}$ & $\begin{array}{l}-360 \\
-100\end{array}$ & $\begin{array}{l}350 \\
610\end{array}$ & $\begin{array}{c}5 \\
255\end{array}$ & $\begin{array}{l}-355 \\
-355\end{array}$ \\
\hline & $\pm 85^{\circ}$ & $\begin{array}{c}-120 \\
930\end{array}$ & $\begin{array}{l}170 \\
680\end{array}$ & $\begin{array}{c}25 \\
805 \\
\end{array}$ & $\begin{array}{c}-145 \\
125 \\
\end{array}$ \\
\hline
\end{tabular}

Table 1 Inner and outer strains for three composite materials and three winding angles.

Strains measured after all cutting operations. 


\begin{tabular}{|l|c|c|c|}
\hline Material & T700/epoxy & E glass/epoxy & R glass/epoxy \\
\hline$E_{1}[\mathrm{GPa}]$ & 155 & 49.5 & 64 \\
\hline $\mathrm{E}_{2}, \mathrm{E}_{3}[\mathrm{GPa}]$ & 9 & 16 & 15.9 \\
\hline$v_{12}, v_{13}$ & 0.27 & 0.26 & 0.26 \\
\hline$v_{23}$ & 0.4 & 0.4 & 0.4 \\
\hline $\mathrm{G}_{12}[\mathrm{GPa}]$ & 5.6 & 5.6 & 6 \\
\hline$\alpha_{1}\left[\mathrm{~K}^{-1}\right]$ & $0.0910^{-6}$ & $8.610^{-6}$ & $8.610^{-6}$ \\
\hline$\alpha_{2}, \alpha_{3}\left[\mathrm{~K}^{-1}\right]$ & $28.810^{-6}$ & $26.410^{-6}$ & $26.410^{-6}$ \\
\hline$\beta_{1}$ & 0 & 0 & 0 \\
\hline$\beta_{2}, \beta_{3}$ & 0.4 & 0.2 & 0.2 \\
\hline
\end{tabular}

Table 2 Properties used for the simulations. 